Pesq. Vet. Bras. 29(7):575-582, julho 2009

\title{
Títulos de anticorpos aglutinantes induzidos por vacinas comerciais contra leptospirose bovina ${ }^{1}$
}

\author{
Gabriela de Godoy Cravo Arduino ${ }^{2 \star}$, Raul José Silva Girio², Fernanda Senter \\ Magajevski ${ }^{2}$ e Gener Tadeu Pereira ${ }^{3}$
}

\begin{abstract}
Arduino G.G.C., Girio R.J.S., Magajevski F.S. \& Pereira G.T. 2009. [Agglutinating antibody titers induced by commercial vaccines against bovine leptospirosis.] Títulos de anticorpos aglutinantes induzidos por vacinas comerciais contra leptospirose bovina. Pesquisa Veterinária Brasileira 29(7):575-582. Departamento de Medicina Veterinária Preventiva e Reprodução Animal, Faculdade de Ciências Agrárias e Veterinárias, Universidade Estadual Paulista, Via de Acesso Paulo Donato Castellane s/n, Jaboticabal, SP 14884-900, Brazil. E-mail: cocaarduino@yahoo.com.br

In the investigation 100 heifers were used, divided into 5 groups of 20 animals each. The four experimental groups were vaccinated using distinct commercial polyvalent bacterines: B, C, D and E, and A group was the control. Samples were collected at days 0 , $3,7,14,21,28,35,42,49,56,63,70,77,84,91,120,150$ and 180 from the first injection of the vaccine. The selection of the animals for the experimental groups was done based on a serological screening with 6 antigens of Leptospira sp. constituted by non-reagent animals. The vaccine titers were monitored using the microscopic agglutination test (MAT) for Canicola, Grippotyphosa, Hardjo, Icterohaemorrhagiae, Pomona and Wolffi serovars. All vaccines used were capable to product agglutinins for the Hardjo and Wolffi serovars observed at 3 days after vaccination, remaining until the 150th day; those serovars induced the highest titres of agglutinins. Vaccine D, in spite of not containing the Wolffi serovar, induced the production of agglutinins to this serovar. Agglutinins to the Canicola serovar were only observed in the animals vaccinated with the $D$ bacterine. Vaccine $D$ induced the highest average titers of antibodies to all tested serovars.
\end{abstract}

INDEX TERMS: Leptospirosis, cattle, vaccine, agglutinins.

RESUMO.- No presente estudo, 100 fêmeas bovinas foram divididas em cinco grupos de 20 animais cada. Os grupos experimentais receberam quatro diferentes vacinas comerciais (B, $C, D$ e $E$ ), e um grupo permaneceu como controle. Amostras foram colhidas no dia da aplicação da primeira dose e nos dias $3,7,14,21,28,35,42$, $49,56,63,70,77,84,91,120,150$ e 180 pós-vacinação (PV). A triagem dos animais foi feita pela análise sorológica com 6 antígenos de leptospiras, escolhendo-se os

\footnotetext{
${ }^{1}$ Recebido em 24 de novembro de 2008.

Aceito para publicação em 20 de março de 2009.

2 Departamento de Medicina Veterinária Preventiva e Reprodução Animal, Faculdade de Ciências Agrárias e Veterinárias (FCAV), Universidade Estadual Paulista (Unesp), Via de Acesso Paulo Donato Castellane s/n, Jaboticabal, SP 14884-900, Brasil. *Autor para correspondência: cocaarduino@yahoo.com.br

${ }^{3}$ Departamento de Ciências Exatas, FCAV, Unesp, Jaboticabal, SP.
}

animais não reagentes. Os títulos de anticorpos foram monitorados pela soroaglutinação microscópica (SAM) com os sorovares Canicola, Grippotyphosa, Hardjo, Icterohaemorrhagiae, Pomona e Wolffi. Todas as vacinas induziram, aos 3 dias PV, títulos de anticorpos aglutinantes para os sorovares Hardjo e Wolffi, que persistiram até o $150^{\circ}$ dia PV. Os sorovares Hardjo e Wolffi induziram os maiores títulos de anticorpos aglutinantes. A vacina $D$, apesar de não possuir o sorovar Wolffi em sua composição foi capaz de induzir anticorpos aglutinantes contra este sorovar. Somente foram detectados anticorpos contra o sorovar Canicola nos animais vacinados com a bacterina $\mathrm{D}$. A vacina que induziu os maiores títulos médios de anticorpos, considerando todos os sorovares testados foi a D.

TERMOS DE INDEXAÇÃO: Leptospirose, vacina, bovinos, aglutininas. 


\section{INTRODUÇÃO}

Entre as enfermidades incriminadas como fonte de perdas econômicas na produção e segurança alimentar está a leptospirose. Caracterizando-se por uma enfermidade de caráter populacional e ambiental, seu controle está intimamente ligado a medidas de prevenção, aplicadas aos animais e ao ambiente no qual os mesmos são mantidos. Das medidas preventivas relacionadas ao manejo, a vacinação é uma das mais importantes, pois pode proporcionar uma imunidade humoral aos animais de forma que estes estejam protegidos contra a manifestação dos sinais clínicos da leptospirose, impedindo que a enfermidade seja transmitida entre os animais e os seres humanos.

As vacinas disponíveis atualmente no mercado brasileiro, em sua maioria, se caracterizam por serem culturas de leptospiras inativadas acrescidas de adjuvantes (Langoni et al. 1999). São compostas pelos sorovares com maior prevalência nos estudos efetuados no país (Siddique \& Shah 1990, Langoni et al. 1999), sendo comum adquirir bacterinas penta e hexavalentes. Entre os sorovares mais utilizados encontram-se o Hardjo, Wolffi, Canicola, Icterohaemorrhagiae, Pomona, Grippotyphosa (Faine et al. 1999) e Bratislava. Há também, disponíveis comercialmente, vacinas contra leptospirose produzidas com a utilização da membrana externa da leptospira (Nardi Júnior et al. 2006), estas sempre estão associadas a outras enfermidades da esfera reprodutiva, tais como rinotraqueíte infecciosa bovina e diarréia bovina a vírus, sendo o seu preço mais elevado quando comparado ao das vacinas somente contra os sorovares de leptospira.

Brenner et al. (1999) explicam que os agrupamentos baseados na antigenicidade (sorogrupos e sorovares) não correspondem aos grupos taxonômicos, baseados nas relações genômicas; a maioria dos sorogrupos contém muitos sorovares ou contém mais de uma espécie (ou genótipo), e a maioria dos grupos de espécies tem sorogrupos representativos e múltiplos, como é o caso dos sorovares Hardjo e Wolffi. Tabata (2002) confirmou essa descrição quando trabalhou determinando a proteção cruzada entre os sorovares Wolffi, Hardjo e Guaricura em hamsters (Mesocricetus auratus). Nardi Júnior et al. (2003) também observaram a reação cruzada entre os sorovares Hardjo e Wolffi quando trabalharam com uma vacina que não continha o sorovar Wolffi em sua composição.

Os anticorpos contra leptospira podem ser detectados no soro sangüíneo dos animais no início das infecções e mais tardiamente no caso das vacinações. A concentração dos anticorpos aumenta à medida que a infecção evolui, ou ainda, no desenvolvimento da resposta induzida pelos antígenos vacinais. As classes de anticorpos que inicialmente são detectadas são IgM e IgA, que em média nos bovinos chegam a concentrações mais elevadas em cerca de sete dias. A classe IgG pode ser detectada por volta de dois dias após o surgimento das anteriores, atingindo a sua magnitude por volta de duas semanas e perdurando por tempo mais prolongado (Thevenon et al. 1987, Tizard 1998).
Rao \& Keshavamurthy (1985), ao utilizarem a prova de soroaglutinação microscópica e o teste de inibição de crescimento de leptospiras in vivo para analisar a resposta sorológica de bezerros bubalinos, vacinados com uma bacterina pentavalente preparada com os sorovares Pomona, Canicola, Hebdomadis, Tarassovi e Shermani, obtiveram a soroconversão contra todos os componentes da vacina no $15^{\circ}$ dia pós-vacinação (PV). Ao avaliarem o perfil sorológico de 17 bezerras búfalas vacinadas com bacterina comercial, Nardi Júnior et al. (2006) observaram aos 15 dias PV títulos detectáveis de aglutininas para os sorovares Canicola, Pomona e Icterohaemorrhagiae. Já Arduino et al. (2004), ao pesquisarem a indução de anticorpos contra leptospira em bovinos vacinados com bacterina polivalente comercial frente a dois esquemas de vacinação, observaram reação à soroaglutinação microscópica (SAM) contra os sorovares Harjo, Wolffi e Pomona aos 15 dias PV.

Entre os fatores que podem influenciar a eficácia das vacinas pode-se destacar a influência dos esquemas de vacinação empregados, a qualidade e a quantidade de microrganismos imunizantes, o grau de similaridade entre os antígenos que compõem a bacterina, o tipo de adjuvante utilizado e a temperatura de conservação e transporte da vacina até a propriedade (Tizard 1998). Favero et al. (1997) reforçaram em seus estudos a idéia de que a concentração antigênica da vacina exerce grande influência na produção de aglutininas pós-vacinais.

Quando a reação de SAM é empregada para o diagnóstico da leptospirose animal adotando-se a diluição inicial dos soros sangüíneos de $1 / 50$, espera-se que dos 60 aos 90 dias após a vacinação os animais comportem-se como não reatores (Faine 1994, Hanson 1997). No entanto, esses critérios não estão totalmente esclarecidos, é possível que exposições a antígenos homólogos ou heterólogos antes da vacinação ocasionem interferências na resposta vacinal. Todavia, as vacinas estimulam a produção de baixos títulos detectáveis pela SAM, que surgem rapidamente e declinam após várias semanas, e a proteção contra a enfermidade e a infecção renal tem sido demonstrada por pelo menos 12 meses em bovinos (Faine et al. 1999).

Guimarães et al. (1982/83) descrevem, que as vacinas contra leptospirose bovina disponíveis no mercado protegem contra as manifestações clínicas da doença, porém não asseguram garantias contra a excreção de leptospiras através das vias urinárias. Bolin et al. (1989) relatam que a vacinação diminui a ocorrência de infecção e transtornos reprodutivos causados pelo sorovar Hardjo sob condições de campo, mesmo não induzindo níveis significativos de anticorpos aglutinantes.

As vacinas contra leptospirose têm sido testadas em bovinos por vários anos, e os relatos sobre sua eficácia são conflitantes. Faine et al. (1999) relatam que resultados de triagens em bovinos têm diferido desde o completo sucesso, significando que todos os animais vacinados estavam protegidos e os controles não, até a completa 
falência, com diferença não significativa entre os grupos de controle e experimental. Autores como Bolin et al. (1989), Favero et al. (1997) e Samina et al. (1997) encontraram quase nenhuma resposta sorológica após a vacinação com bacterinas comerciais. Porém, destacam-se os resultados obtidos por Del Fava et al. (2004) quando trabalharam com bovinos da raça Nelore manejados extensivamente. Esses autores observaram que a soropositividade para leptospira não interferiu no coeficiente de prenhez, coeficiente de parição, de natimortalidade e características de desempenho de matrizes reagentes e não reagentes, sendo o escore corporal dos bovinos a variável responsável pela diferença dos índices de produtividade observados. Ou seja, bovinos de corte sororreagentes contra Leptospira spp. e não vacinados contra leptospirose, sob manejo zootécnico extensivo, apresentaram bons coeficientes de prenhez, parição e natalidade, independentemente de raça, grupo genético e faixa etária.

O modo de preparação empregado pela indústria na fabricação das vacinas interfere nos títulos de anticorpos induzidos e na sua duração, conforme demonstraram Nardi Júnior et al. (2003). Esses autores compararam os títulos de anticorpos detectados pela SAM induzidos por uma bacterina (bactéria total inativada acrescida de adjuvante) e uma vacina fabricada com a membrana externa da leptospira em bubalinos. Embora as duas vacinas tenham sido capazes de induzir uma resposta sorológica detectável, a de membrana externa foi superior à bacterina com relação à magnitude de títulos de anticorpos e sua duração.

Nos dias atuais a imunização por meio da vacinação é uma das práticas mais relevantes no manejo sanitário dos bovinos, com reflexos imediatos e diretos no retorno econômico da atividade, na garantia do excelente padrão sanitário do rebanho e na abertura e manutenção dos mercados. Embora represente um dos menores custos dentro do processo produtivo, de $2-5 \%$, a vacinação pode ser decisiva para a obtenção de bons resultados na produção animal. Por este motivo o presente trabalho teve por objetivo acompanhar a dinâmica da produção de anticorpos aglutinantes contra a leptospirose induzidos por quatro vacinas comerciais disponíveis no mercado brasileiro, comparando o desempenho da indução de anticorpos aglutinantes, a resposta humoral pela pesquisa de aglutininas contra cada sorovar contido na vacina utilizada e a duração dos títulos por meio da soroaglutinação microscópica. Não há relatos na literatura de trabalhos comparando diferentes vacinas comerciais.

\section{MATERIAL E MÉTODOS}

O presente estudo foi conduzido em uma propriedade no Município de Morro Agudo, localizado na região Norte do Estado de São Paulo. Os animais estudados foram 100 fêmeas bovinas com idade de 16-20 meses provenientes de cruzamento entre as raças Nelore e Simental, criadas e recriadas em outra propriedade no Estado do Mato Grosso do Sul para serem utilizadas como receptoras de embriões. Os animais foram submetidos à quarentena logo após a sua chegada da propriedade de recria.

Procedeu-se então à colheita de amostras de sangue para a prova de soroaglutinação microscópica (SAM), como preconiza Cole et al. (1973), para avaliar a resposta humoral contra os sorovares contidos nas quatro vacinas, comparar os desempenhos das mesmas e a duração dos títulos de anticorpos detectáveis.

Foram efetuadas duas colheitas de amostras do total dos animais, com duas semanas de intervalo entre elas, para certificar que os animais em estudo não eram reagentes contra leptospiras. Foi realizada, em cada amostra de soro, triagem com seis variantes sorológicas de Leptospira interrogans (Canicola, Hardjo, Grippotyphosa, Icterohaemorrhagiae, Pomona e Wolffi). Selecionaram-se somente animais não reagentes, os quais não foram tratados e nem vacinados previamente contra leptospirose, somente monitorados. Consideraram-se como animais não reagentes aqueles cujos exames sorológicos não apresentaram reatividade contra os seis sorovares utilizados como antígeno. Para confirmar a ausência de reação, foi efetuada colheita de sangue no momento da aplicação da vacina, tendo certeza de que os animais não haviam sido infectados.

O total de animais utilizados nos grupos experimentais foi de 100, distribuídos em igual número (20 animais) nos cincos grupos escolhidos aleatoriamente. Para tanto, foram testados 140 animais do lote durante o processo de triagem. Todos os animais foram mantidos com a mesma dieta e no mesmo local, para evitar interferências externas aos tratamentos.

As vacinas utilizadas constituíram-se de quatro bacterinas polivalentes disponíveis no mercado, continham em sua composição os sorovares Canicola, Grippotyphosa, Hardjo, Icterohaemorrhagiae, Pomona e Wolffi, com exceção da vacina D que não continha a adição do sorovar Wolffi.

O esquema de vacinação empregado constituiu-se de uma primeira dose no dia zero e uma segunda dose, denominada reforço, 28 dias após a primeira vacinação. O primeiro grupo foi constituído por 20 fêmeas que receberam a aplicação de placebo ( $3 \mathrm{~mL}$ de solução fisiológica, tratamento A) via subcutânea (SC). O segundo grupo $(B)$ recebeu a aplicação da vacina $B$, na dose de $3 \mathrm{~mL}$ via SC. O terceiro grupo $(\mathrm{C})$ foi vacinado com a bacterina denominada $C$ na dose de $5 \mathrm{~mL}$, via intramuscular (IM). A vacina $D$ foi a aplicada nos animais do quarto grupo experimental (D), sendo a via de aplicação a $\mathrm{IM}$, e a dosagem $2 \mathrm{~mL}$. O último grupo (quinto, E) recebeu $5 \mathrm{~mL}$ da vacina $\mathrm{E}$ via $\mathrm{SC}$.

As colheitas de amostras foram efetuadas nos dias zero (momento da aplicação das vacinas), 3, 7, 14, 21, 28, 35, 42, $49,56,63,70,77,84,91,120,150$ e 180 pós-vacinação (PV). As amostras de soro sangüíneo foram examinadas pela prova de SAM contra seis sorovares diferentes de Leptospira: Canicola, Hardjo, Grippotyphosa, Icterohaemorrhagiae, Pomona e Wolffi como preconizado por Santa Rosa (1970). Durante a leitura, foi avaliado o grau de aglutinação, segundo o critério recomendado pelo Centro Panamericano de Zoonoses (1985). Foram consideradas reagentes as amostras de soros sangüíneos que aglutinaram pelo menos $50 \%$ das leptospiras na diluição final de 1/100. Em seguida, as amostras reagentes foram tituladas até 1.600 , diluídas na proporção geométrica de razão dois. Foi considerada como título final a maior diluição que apresentou pelo menos $50 \%$ de leptospiras aglutinadas no campo microscópico.

Os títulos de anticorpos obtidos pela SAM foram categori- 
camente pareados de acordo com as variáveis tempo (em dias decorridos após a primeira aplicação da vacina), tratamento (A, B, C, D e E) e sorovar (Canicola, Hardjo, Grippotyphosa, Icterohaemorrhagiae, Pomona e Wolffi). As médias foram obtidas pelos logaritmos dos títulos observados e foram confrontadas pelo teste de Tukey, testando as hipóteses com $5 \%$ de confiabilidade. A tabulação e o tratamento dos dados foram efetuados com o auxílio de um pacote estatístico denominado SAS System, conforme preconizam os autores Dias (1997) e Schlotzauer \& Littell (1997).

\section{RESULTADOS}

Os soros dos animais utilizados neste estudo foram considerados não reagentes à prova de soroaglutinação microscópica (SAM) frente aos antígenos dos sorovares Canicola, Grippotyphosa, Hardjo, Icterohaemorrhagiae, Pomona e Wolffi quando examinados preliminarmente para a formação dos grupos experimentais.

A análise estatística dos resultados obtidos demonstrou que houve interação entre o tempo, o sorovar e a vacina aplicada $(p<0,05)$ quando comparados os logaritmos das médias de títulos pelo teste de Tukey. Demonstrando que houve influência dos fatores citados na indução da produção de anticorpos após a aplicação das vacinas nos animais.

A partir do $21^{\circ}$ até o $120^{\circ}$ dia pós-vacinação (PV) foi observada média de títulos $(1,29)$ detectados pela SAM com diferença significativa $(p<0,05)$ quando comparada às médias até o $14^{\circ}$ dia $\mathrm{PV}$. O valor das médias de títulos continuou a aumentar até o dia $42 \mathrm{PV}(1,59)$, quando apresentou uma pequena queda, voltando aumentar no dia 63 PV $(1,58)$. A maior média de títulos observada foi a do dia 77 PV $(1,67)$, a partir daí voltou a declinar, apresentando diferenças significativas $(p<0,05)$ até o dia $180 \mathrm{PV}$, quando os animais não apresentavam mais títulos de anticorpos detectáveis à SAM.

Quando observadas as médias gerais dos logaritmos de títulos contra cada sorovar testado pela SAM, verificou-se que o sorovar Canicola $(0,01)$ e o Grippotyphosa $(0,15)$ foram os que induziram as menores médias de títulos à SAM, não diferindo significativamente entre si $(p>0,05)$. Os sorovares Icterohaemorrhagiae e Pomona apresentaram médias de títulos de 0,49 e 0,71, respectivamente, também não apresentando diferença significativa $(p>0,05)$, porém diferiram $(p<0,05)$ dos títulos observados contra os sorovares Canicola e Grippotyphosa. Os sorovares que induziram os maiores títulos médios de anticorpos foram o Hardjo $(2,49)$ e Wolffi $(2,70)$, que não diferiram significativamente $(p>0,05)$ entre si, porém diferiram dos demais $(p<0,05)$.

Levando-se em consideração todos os logaritmos das médias de títulos pela SAM observados para cada vacina o tratamento A, grupo de controle, não apresentou títulos de anticorpos detectáveis pela SAM. Os tratamentos $\mathrm{C} \mathrm{e}$ E apresentaram médias de 1,10 e 1,09, respectivamente, não diferindo $(p>0,05)$ entre si, porém diferindo significativamente do grupo controle. O tratamento B $(1,45)$ foi capaz de causar a indução de títulos de anticorpos detectáveis pela SAM, porém foi menor que os provocados pelo tratamento $D(1,82)$, que apresentou títulos de maior amplitude, diferindo significativamente $(p<0,05)$ dos demais observados.

O sorovar Canicola não induziu produção significativa $(p>0,05)$ de títulos de anticorpos detectáveis pela SAM. $O$ tratamento $D$ foi o único capaz de induzir nos animais alguma produção de anticorpos contra esse sorovar nos dias 14 e 28 PV, com médias de 0,2308 e 0,6923, respectivamente, porém estas não diferiram significativamente $(p>0,05)$ das demais.

Na dinâmica dos títulos de anticorpos detectados pela SAM contra o sorovar Grippotyphosa, em logaritmo, somente o tratamento D no dia 84 PV foi capaz de induzir a produção significativa $(p<0,05)$ de títulos de anticorpos detectáveis pela SAM $(2,0289)$. Os animais desse tratamento também apresentaram títulos nos dias $14 \mathrm{PV}$ $(0,2308)$ e nos dias 35 a 150 PV (variando de 0,2308 a 2,0289 ). Os animais inoculados com o tratamento $C$ apresentaram anticorpos contra o sorovar Grippotyphosa nos dias $35(0,2308)$ e $42(0,2308)$ PV, e os inoculados com o tratamento $E$, nos dias $49(0,2308), 56(0,2652)$ e 63 $(0,2308) \mathrm{PV}$.

Contra o sorovar Hardjo, todos os tratamentos, com exceção do grupo de controle (tratamento A), apresentaram dinâmica semelhante de indução de produção de anticorpos detectáveis pela SAM, havendo um aumento gradual na expressão de títulos até o dia $21 \mathrm{PV}$, com queda dos títulos até o dia $56 \mathrm{PV}$, voltando a aumentar novamente até atingir o título médio máximo no dia $84 \mathrm{PV}$, que foi apresentado pelos animais inoculados com o tratamento $\mathrm{D}(5,3501)$. Após os 84 dias PV houve uma gradual diminuição da expressão de títulos, até a ausência de títulos detectáveis pela SAM no dia 180 PV. As maiores médias de títulos na maioria das datas de colheita foram apresentadas pelo tratamento $D$, seguindo os tratamentos $\mathrm{B}, \mathrm{C}$ e posteriormente o tratamento $\mathrm{E}$. Todas as vacinas foram capazes de induzir médias de títulos significativas $(p<0,05)$ de anticorpos durante o período do estudo.

Todas as vacinas foram capazes, em algum momento, de induzir a produção significativa $(p<0,05)$ de anticorpos detectáveis pela SAM contra o sorovar Icterohaemorrhagiae, porém de menor magnitude e duração quando comparados com aquela provocada pelo sorovar Hardjo. $O$ tratamento $C$ foi o que induziu nos animais médias de anticorpos por menor tempo, apenas do dia 49 ao 91 PV. $O$ tratamento $E$ iniciou a indução de anticorpos nos animais aos 35 dias PV, atingindo média de títulos de 1,9149, e a partir daí declinando até o desaparecimento no dia 84 $P V$. Já para o tratamento $B$ somente foram observados títulos a partir do dia 42 PV $(1,1538)$, chegando a 1,9600 (56 PV) e declinando até desaparecer no dia $84 \mathrm{PV}$. O tratamento $D$ foi o que provocou a maior indução de anticorpos detectáveis pela SAM, durante maior período de tempo. Houve uma pequena detecção de títulos no dia 14 $P V$, porém estes não foram significativos $(p>0,05)$. Após 

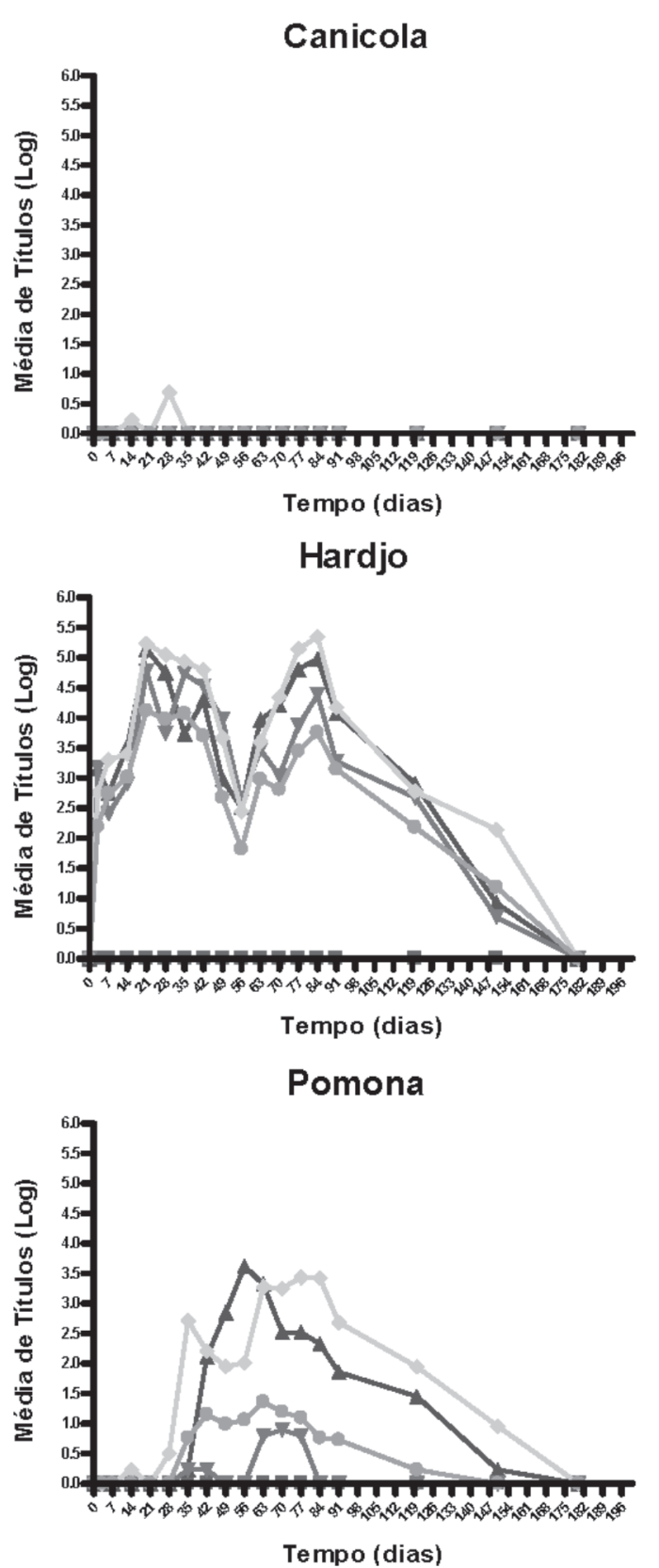
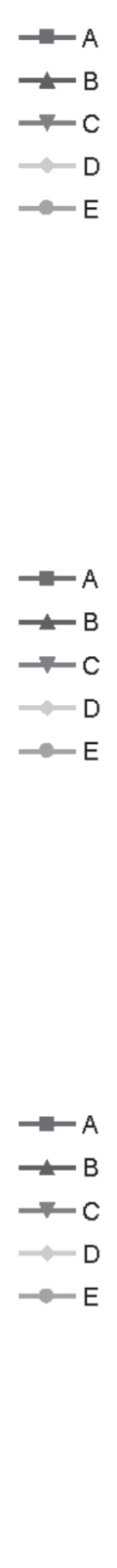

\section{Grippotyphosa}

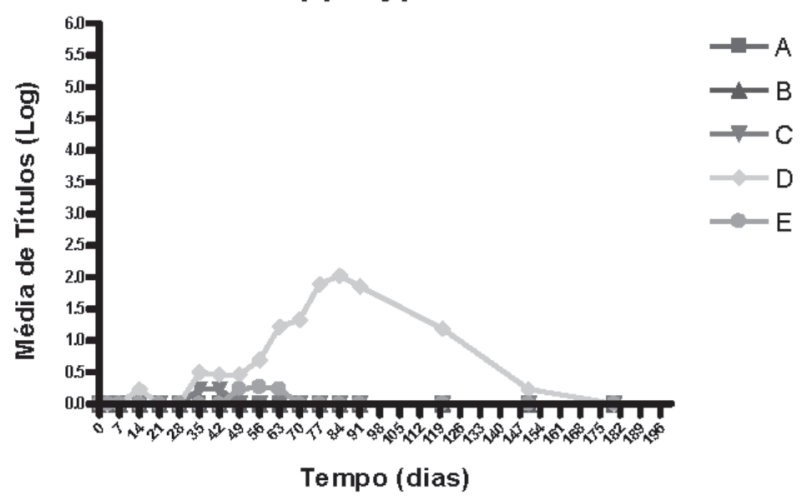

Icterohaemorrhagiae

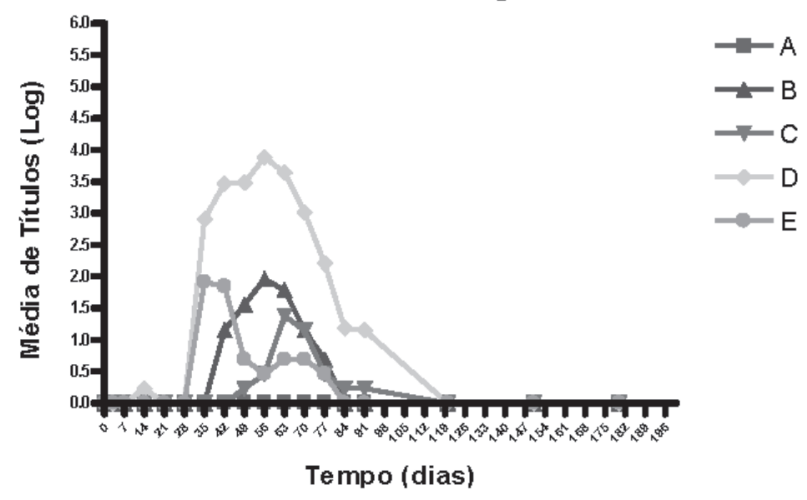

Wolffi

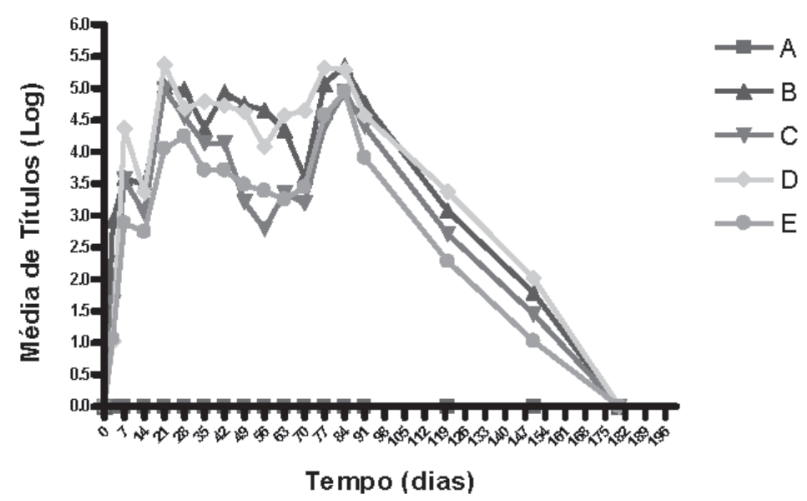

Fig.1. Médias dos logaritmos dos títulos detectados pela SAM contra os sorovares testados de acordo com o tratamento aplicado e a data de colheita da amostra. Jaboticabal/SP, 2003.

o dia $35 \mathrm{PV}$, os animais apresentavam altos valores de títulos de anticorpos $(2,9068)$, e nos dias $49(3,4821)$ e 56 $(3,8855)$ as respostas de anticorpos foram significativas quando comparadas às demais vacinas, atingindo o ápice no dia 56 PV $(3,8855)$, declinando lentamente até a não detecção de títulos de anticorpos no dia 120 PV.

Com relação à resposta vacinal de anticorpos contra o sorovar Pomona nos animais vacinados, o tratamento $D$ foi o que primeiro induziu nos animais a produção de títulos médios de anticorpos detectáveis pela SAM aos 14 dias PV, porém a média de títulos de anticorpos não foi significativa $(p>0,05)$, declinando para zero aos 21 dias
PV e voltando a serem detectados aos 28 dias PV $(0,4959)$ e atingindo a sua expressão máxima de anticorpos aos 77 dias PV $(3,4381)$. Logo após, diminuiu e não apresentou níveis de anticorpos detectáveis aos 180 dias PV, foi o tratamento que demonstrou a existência de anticorpos circulantes por um maior período de tempo e com significância $(p<0,05)$ por maior tempo. $O$ tratamento $B$ foi o que induziu nos animais maior título médio de anticorpos, 3,6204 aos 56 dias PV, no dia 35 PV houve o início da detecção de anticorpos $(0,2308)$, porém a quantidade média de anticorpos expressados pelos animais só foi significativa $(p<0,05)$ aos 42 dias PV $(2,1112)$, che- 
gando ao maior valor aos 56 dias PV $(3,6204)$, depois declinando gradativamente até não induzir títulos de anticorpos significativos aos 91 dias PV $(1,8563)$ e ausência de títulos aos 180 dias PV. O tratamento E teve um comportamento semelhante ao do tratamento $D$, porém de menor amplitude e duração. Os animais submetidos ao tratamento $C$ somente apresentaram titulação de anticorpos pela SAM em cinco momentos, aos 35 dias PV $(0,2308), 42$ dias PV $(0,2308)$, voltando a apresentar aos 63 dias PV $(0,7955), 70$ dias PV $(0,8991)$ e 77 dias PV $(0,7955)$, porém em nenhum momento a identificação do título médio de anticorpos foi significativa $(p>0,05)$.

Todas as vacinas foram capazes de provocar nos animais uma resposta de anticorpos aglutinantes detectados pela SAM $(p<0,05)$ contra o sorovar Wolffi. As respostas de anticorpos aglutinantes dos animais submetidos às vacinas foram todas significantes aos 7 dias PV $(p<0,05)$, com exceção do tratamento $B$ que teve significância $(p<0,05)$ aos 3 dias PV. O valor máximo de média de títulos de anticorpos foi o dos animais submetidos ao tratamento $\mathrm{D}$ aos 21 dias PV $(5,3732)$. O comportamento da dinâmica de títulos de anticorpos foi semelhante ao do sorovar Hardjo, com dois picos de anticorpos, o primeiro no $28^{\circ}$ dia e o segundo no $84^{\circ}$ dia PV, para depois apresentar um declínio até atingir títulos não detectáveis pela SAM aos 180 dias PV. Porém, com exceção do tratamento $D$, para o qual os animais ainda apresentavam títulos significativos de anticorpos aos 150 dias PV $(p<0,05)$, para as demais vacinas os títulos de anticorpos aglutinantes detectados pela SAM somente foram significativos $(p<0,05)$ quando comparados ao grupo de controle até os 120 dias PV.

Quando se analisa a resposta de anticorpos aglutinantes, induzidos nos animais pela aplicação das diferentes vacinas, de acordo com os sorovares testados, há uma dinâmica semelhante entre os sorovares Hardjo e Wolffi, o mesmo não ocorrendo com os demais sorovares (Canicola, Grippotyphosa, Icterohaemorrhagiae e Pomona).

\section{DISCUSSÃO}

As vacinas utilizadas neste estudo, em sua maioria, foram hexavalentes, contendo os sorovares Canicola, Grippotyphosa, Hardjo, Icterohaemorrhagiae, Pomona e Wolffi, semelhante ao descrito por Faine et al. (1999) e Langoni et al. (1999). Exceção feita à vacina D, que é pentavalente, não sendo adicionado o sorovar Wolffi, porém os animais foram capazes de produzir anticorpos aglutinantes detectáveis pela soroaglutinação microscópica (SAM) contra este sorovar de forma significativa.

Os animais não apresentaram uma mesma magnitude de resposta em anticorpos aglutinantes detectáveis pela SAM contra os sorovares utilizados como antígenos, quando considerados os logaritmos dos títulos de anticorpos. Siddique \& Shah (1990) afirmam que as vacinas não induzem uma mesma resposta sorológica contra todos os sorovares nelas contidos, podendo isso ocorrer devido a uma diferença na concentração antigênica final, ou pela supressão da resposta antigênica causada por um sorovar sobre outro presente na vacina. Tabata (2002) também cita que há variações no poder imunogênico segundo a estirpe de leptospira empregada para a produção das bacterinas.

De maneira geral, aos 14 dias PV todos os animais foram capazes de produzir títulos de anticorpos detectáveis pela SAM contra os sorovares contidos nas bacterinas; somente os sorovares Hardjo e Wolffi induziram nos animais títulos de anticorpos aglutinantes aos três dias PV, semelhante ao que foi observado por Arduino et al. (2004) e Nardi Júnior et al. (2006).

Ao contrário do que foi detectado por Nardi Júnior et al. (2006), durante este trabalho só foram observadas reações aos sorovares Canicola, Pomona e Icterohaemorrhagiae induzidas pela vacina $D$ aos 14 dias $P V$, sendo estas de baixa amplitude, quando comparadas às dos sorovares Hardjo e Wolffi. Arduino et al. (2004), ao confrontarem o perfil sorológico contra leptospira frente a dois esquemas de vacinação, não obtiveram títulos de anticorpos contra os sorovares Canicola e Grippotyphosa em bovinos leiteiros quando utilizaram uma bacterina comercial durante todo o período observado.

No estudo de Nardi Júnior et al. (2006), não houve detecção à SAM de anticorpos aglutinantes para o sorovar Hardjo até o $60^{\circ}$ dia PV, o qual se encontrava em altos títulos para todas as vacinas testadas neste trabalho.

Somente o tratamento $D$ foi capaz de induzir a produção de anticorpos aglutinantes contra o sorovar Canicola, porém a expressão de anticorpos foi de baixa amplitude e de curta duração, sendo estas no $14^{\circ}$ e no $28^{\circ}$ dias PV.

Os tratamentos C, D e E foram capazes de induzir uma resposta de anticorpos detectáveis contra o sorovar Grippotyphosa, porém somente o tratamento $D$ foi capaz de provocar uma resposta estatisticamente significativa $(p<0,05)$, que se manteve por maior tempo, até 120 dias PV. Favero et al. (1997) citam que contra esse sorovar verificou-se um comportamento irregular na curva de anticorpos, já Arduino et al. (2004) não observaram reação à SAM durante o período do experimento, tanto em animais vacinados com somente uma dose, como com dose de reforço 30 dias após a primeira inoculação.

Contrariando as observações de Favero et al. (1997), aos 14 dias PV o tratamento D foi capaz de induzir resposta de anticorpos aglutinantes detectáveis pela SAM, porém todas as vacinas, com exceção do grupo de controle (tratamento A), foram capazes de induzir a produção de anticorpos aglutinantes detectáveis até o $77^{\circ}$ dia PV pelo menos. Da mesma forma observada no trabalho de Favero et al. (1997), os títulos de anticorpos mais elevados foram contra os sorovares Hardjo e Wolffi.

Em contrapartida às observações de Nardi Júnior et al. (2006) que observou a maior amplitude de títulos detectáveis pela SAM aos 60 dias PV, os maiores títulos observados se deram aos 84 dias PV. A aplicação de dose de reforço aumentou a expressão de títulos de anticorpos aglutinantes, da mesma forma que Arduino et al. (2004) 
comprovaram ao testar dois esquemas de vacinação (com e sem dose de reforço).

Neste estudo, o emprego da SAM demonstrou haver títulos de anticorpos já aos três dias PV contra os sorovares Hardjo e Wolffi de pelo menos 100, e esses perduraram até $0150^{\circ}$ dia $\mathrm{PV}$ contra ambos os sorovares, enquanto contra os demais sorovares a expressão de anticorpos aglutinantes detectáveis pela SAM se deu por menor tempo. A amplitude de títulos também foi maior quando comparada aos resultados observados por Nardi Júnior et al. (2006).

Quando se observam as respostas de anticorpos contra os sorovares Hardjo e Wolffi pôde-se perceber um padrão de expressão de anticorpos aglutinantes. No terceiro dia PV há o início dos títulos, que aumentam até o dia $21 \mathrm{PV}$, produzindo um primeiro pico de anticorpos, depois havendo uma pequena queda por volta do $56^{\circ}$ dia PV, para voltar a aumentar em magnitude até o dia 84 PV. Nardi Júnior et al. (2003) observaram picos de anticorpos contra a maioria dos sorovares ao redor do $45^{\circ} \mathrm{e}$ $60^{\circ}$ dias PV, coincidindo com os dias 15 e $30 \mathrm{PV}$, quando trabalharam com búfalas. Depois os títulos de anticorpos declinaram até a não-detecção pela SAM aos 180 dias PV. Essa queda de anticorpos aglutinantes contra os sorovares Hardjo e Wolffi após a vacinação (reforço) pode ser devido ao fato de haver uma neutralização dos anticorpos séricos existentes nos animais previamente vacinados (Tizard 1998). Essa observação também foi verificada por Favero et al. (1997) em bovinos. O conjunto de resultados revelou que a presença de aglutininas prévacinais (reforço) exerceu uma pequena influência no perfil de aglutininas pós-vacinais, obtidas com as variantes Hardjo, Wolffi e Icterohaemorrhagiae, havendo uma redução significativa dos níveis de aglutininas pós-vacinais contra o sorovar Pomona. Nardi Júnior et al. (2006) não observaram este padrão de comportamento quando aplicaram doses de reforço nos animais aos 30 e 210 dias após a primeira inoculação.

Como já era esperado, no grupo controle não houve a indução da produção de anticorpos aglutinantes detectáveis pela SAM, pois se tratou do grupo que recebeu apenas a inoculação de solução fisiológica.

O fato de não se observar uma mesma resposta sorológica contra todos os sorovares foi relatado por Siddique \& Shah (1990) e Tabata et al. (2002), e isso pode ocorrer devido a uma diferença na concentração antigênica final da vacina ou pela supressão da resposta antigênica causada pela predominância de um sorovar sobre um outro presente na vacina.

\section{CONCLUSÕES}

Pelos resultados obtidos nas condições em que foi realizado o presente estudo conclui-se que:

As quatro vacinas comercias administradas aos animais com dose de reforço foram capazes de induzir uma resposta estatisticamente significante de anticorpos aglutinantes. O tempo decorrido após a aplicação das vaci- nas, o tipo de vacina e o sorovar contido em cada vacina influenciou a resposta de títulos de anticorpos aglutinantes detectados pela soroaglutinação microscópica (SAM), embora os animais não tenham apresentado uma mesma magnitude de resposta em anticorpos aglutinantes detectáveis pela SAM contra os sorovares utilizados como antígenos, quando considerados os logaritmos dos títulos de anticorpos.

Os sorovares Hardjo e Wolffi foram os que induziram melhores respostas, tanto em magnitude quanto em duração contra todas as vacinas. Sendo que a pior resposta foi contra o sorovar Canicola, que foi capaz somente de induzir nos animais uma baixa resposta contra a vacina $D$.

Os sorovares Hardjo e Wolffi apresentaram resultados satisfatórios na indução de títulos de anticorpos aglutinantes e reação cruzada entre eles.

A detecção de anticorpos pela SAM teve seu início aos 3 dias PV contra os sorovares Hardjo e Wolffi e mais tardiamente contra os demais, observaram-se títulos de anticorpos pela SAM até o dia 120 PV, não necessariamente contra todos os sorovares.

\section{REFERÊNCIAS}

Arduino G.G.C., Girio R.J.S., Freire M.M. \& Marchiori Filho M. 2004. Anticorpos contra Leptospira spp. em bovinos leiteiros vacinados com bacterina polivalente comercial: perfil sorológico frente a dois esquemas de vacinação. Ciência Rural 34(3):865-871.

Bolin C.A., Thiermann A.B., Handsaker A.L. \& Foley J.W. 1989. Effect of vaccination with a pentavalent leptospiral vaccine on Leptospira interrogans serovar Hardjo type Hardjo-bovis infection on pregnant cattle. Am. J. Vet. Res. 50(1):161-165.

Brenner D.J., Kaufmann A.F., Sulzer K.R., Steigerwalt A.G., Rogers F.C. \& Weyant R.S. 1999. Further determination of DNA relatedness between serogroups and serovars in the family Leptospiriaceae with a proposal for Leptospira alexanderi sp. nova and four new Leptospira genomospecies. Int. J. Syst. Bacteriol. 49:839-858.

Centro Panamericano de Zoonosis 1985. Manual de Métodos para el Diagnóstico de Laboratório de la Leptospirosis. Nota Técnica 30, Washington, DC, p.15-25.

Cole J.R., Sulzer C.R. \& Pursell A.R. 1973. Improved microtechnique for leptospiral microscopic agglutination test. Appl. Microbiol. 25:976980.

Del Fava C., Vasconcellos S.A., D'Angelino J.L., Morais Z.M., Figueiredo L.A., Razook A.G., Cyrillo J.N.S.G., Oliveira J.V. \& Reichert R.H. 2004. Coeficientes reprodutivos e soropositividade para Leptospira spp. em um rebanho bovino de corte no Estado de São Paulo, Brasil. Ars Vet. 20(1):52-61.

Dias C.T.S. 1997. Estatística Básica através do SAS para Windows. Escola Superior de Agricultura "Luiz de Queiroz", Piracicaba, p.83101.

Faine S. 1994. Leptospira and Leptospirosis. CRC Press, Melbourne. 353p.

Faine S., Adler B., Bolin C. \& Perolat P. 1999. Leptospira and Leptospirosis. $2^{\underline{a}}$ ed. MedSci, Melbourne. 353p.

Favero A.C.M., Miyaki C.M., Mangerona A.C.S., Alessi L.J., Morais Z.M. \& Vasconcelos S.A. 1997. Aglutininas pós-vacinais em bovinos imunizados com bacterina tetravalente contra leptospirose. Arqs Inst. Biológico, São Paulo, 64(2):45-55.

Guimarães M.A., Cortês J.A., Vasconcellos S.A. \& Ito F. H. 1982/83. Epidemiologia e controle da leptospirose em bovinos: papel do porta- 
dor e seu controle terapêutico. Comun. Cient. Fac. Med. Vet. Zootec. USP 6(7):21-34.

Hanson L.E. 1997. Immunology of bacterial diseases, with special reference to leptospirosis. J. Am. Vet. Med. Assoc. 170(9):991-994.

Langoni H., Del Fava C., Cabral K.G., Silva A.V. \& Chagas S.A.P. 1999. Aglutininas antileptospíricas em búfalos do Vale do Ribeira, Estado de São Paulo. Ciência Rural 29:305-307.

Nardi Júnior G., Genovez M.E., Ribeiro M.G., Jorge A.M., Castro V. \& Carreira R.C. 2003. Níveis de aglutininas anti-leptospira no soro de búfalas (Bubalus bubalis) vacinadas com dois tipos de vacinas comerciais anti-leptospirose: resultados parciais. Arqs Inst. Biológico, São Paulo, 70(3):1-4.

Nardi Júnior G., Ribeiro M.G., Vasconcellos S.A., Megid J., Jorge A.M., Geronutti L. \& Morais Z.M. 2006. Perfil de aglutininas anti-Leptospira em bezerras búfalas vacinadas com bacterina pentavalente comercial contra leptospirose. Arq. Bras. Med. Vet. Zootec. 58(3):299-304.

Rao A.S. \& Keshavamurthy B.S. 1985. Study of the immune response of buffalo calves to heat-killed pentavalent leptospiral vaccine. Indian Vet. J. 62:357-361.
Samina I., Brenner J., Moalem U., Berenstein M., Cohen A. \& Peleg B.A. 1997. Enhanced antibody response in cattle against Leptospira hardjo by intradermal vaccination. Vaccine. 15(12/13):1434-1436.

Santa Rosa C.A. 1970. Diagnóstico laboratorial das leptospiroses. Revta Microbiol. 1(2):97-109.

Schlotzauer S.D. \& Littell R.C. 1997. SAS system for elementary statistical analysis. 2nd ed. SAS Institute, Cary, p.30-73, 245-257.

Siddique I.H. \& Shah S.M. 1990. Evaluation of polyvalent leptospiral vaccine in hamsters. Indian Vet. J. 67:1006-1010.

Tabata R. 2002. Proteção cruzada entre bacterinas antileptospirose produzidas com três representantes do sorogrupo Sejroe: ensaio experimental em hamsters (Mesocricetus auratus). Dissertação de Mestrado em Epidemiologia Experimental e Aplicada às Zoonoses. Faculdade de Medicina Veterinária e Zootecnia, USP, São Paulo. 70p.

Thevenon J., Morlet B., Costa R. \& Lambert C. 1987. Kinetics of leptospirosis and antibody rates: A study conducted on cattle at the Port Laguerre Livestock Research Centre. Rev. Elev. Med. Vet. Nouv. 10:7-12.

Tizard I.R. 1998. Imunologia Veterinária. 5aㅡ ed. Roca, São Paulo, p.273293. 